\title{
Risk factors for intestinal metaplasia in concomitant gastric and duodenal ulcer disease
}

\author{
JUN-BO HONG ${ }^{1 *}$, LIANG XIA ${ }^{1 *}$, WEI ZUO ${ }^{2 *}$, AN-JIANG WANG ${ }^{1}$, SHAN XU $^{3}$, HUI-FANG XIONG ${ }^{1}$, \\ YOU-XIANG CHEN ${ }^{1}$, XUAN ZHU $^{1}$ and NONG-HUA LU ${ }^{1}$ \\ Departments of ${ }^{1}$ Gastroenterology, ${ }^{2}$ Respiratory Medicine and ${ }^{3}$ Pathology, \\ The First Affiliated Hospital of Nanchang University, \\ Nanchang, Jiangxi 330006, P.R. China
}

Received September 29, 2013; Accepted January 23, 2014

DOI: $10.3892 /$ etm.2014.1507

\begin{abstract}
The aim of this study was to estimate the prevalence and risk factors of intestinal metaplasia (IM) in concomitant gastric and duodenal ulcer (CGDU) disease by retrospectively reviewing consecutive patients who had undergone esophagogastroduodenal endoscopy. Patients who received the endoscopic diagnosis of CGDU disease were selected for analysis and the recorded demographic, endoscopic, clinical and outcome data, including data on the development of IM, were extracted. Associations of the various parameters with IM were estimated by logistic regression analysis and described by the odds ratio (OR) with a $95 \%$ confidence interval (CI). Among the total 204,073 consecutive patients screened, 2,397 (1.2\%) were diagnosed with CGDU disease. Following application of the exclusion criteria, a total of 2,149 cases were included in the study. The IM prevalence was $8.4 \%$, represented by 153 mild cases, 26 moderate cases and one severe case. Multivariate analysis identified age $\geq 50$ years $\left(\mathrm{OR}=2.606,95 \% \mathrm{CI}=1.889-3.597, \chi^{2}=34.000, \mathrm{P}<0.001\right)$, ulcer at the gastric incisura $(\mathrm{OR}=2.644,95 \% \mathrm{CI}=1.926-3.630$, $\left.\chi^{2}=36.142, \mathrm{P}<0.001\right)$ and Helicobacter pylori $(H$. pylori $)$ infection $\left(\mathrm{OR}=2.338,95 \% \mathrm{CI}=1.573-3.474, \chi^{2}=17.648, \mathrm{P}<0.001\right)$ as independent risk factors for the development of IM. In addition, the moderate and severe IM grades were more frequently detected in males than in females $(18.8 \%$ vs. $5.8 \%$; OR=3.769, 95\% CI=1.083-13.121, $\left.\chi^{2}=4.887, \mathrm{P}=0.036\right)$. IM in patients with CGDU disease is not uncommon. CGDU patients with
\end{abstract}

Correspondence to: Professor Nong-Hua Lu, Department of Gastroenterology, The First Affiliated Hospital of Nanchang University, 17 Yongwai Zheng Street, Nanchang, Jiangxi 330006, P.R. China

E-mail: allen2005066@sohu.com

\section{*Contributed equally}

Key words: Helicobacter pylori infection, risk factors, concomitant gastric and duodenal ulcers, intestinal metaplasia ongoing $H$. pylori infection, gastric incisura involvement, older age and/or male gender may be at a higher risk of IM.

\section{Introduction}

Gastric cancer (GC), the second and fourth most common type of cancer in males and females respectively, is one of the leading causes of cancer mortalities worldwide (1-5). The intestinal type of GC develops through a cascade of well-defined and recognizable precursors [inflammation-atrophy-intestinal metaplasia (IM)-dysplasia-carcinoma sequence] (6). The annual incidence of GC within five years after diagnosis is appreciable in patients with atrophic gastritis $(0.1 \%)$, IM $(0.25 \%)$, mild-to-moderate dysplasia $(0.6 \%)$ and severe dysplasia (6.0\%) (7). In addition, GC development has been reported to occur $>10.9$-fold more frequently in the presence of IM (8). These findings indicate that IM is an important turning point in the development of GC. Thus, risk factors that are closely associated with IM should be determined in order to monitor or prevent GC onset.

Peptic ulcer disease (PUD), including gastric ulcers (GUs) and duodenal ulcers (DUs), is mainly caused by Helicobacter pylori (H. pylori) infection (9-11). Previous studies have characterized GUs as a precancerous condition of GC (12), shown that a past history of GU confers an increased risk of GC (13), and revealed a high frequency of IM detection in the GU patient population (14), indicating that IM is a key pathology that requires particular attention in the presence of GUs. However, DUs are rarely associated with IM, and thus are considered to play a minimal role in the development of GC $(15,16)$. Furthermore, a study indicates that factors associated with DUs may be protective against GC (17). However, patients with DUs have an increased risk of GC in the presence of IM at the antrum and corpus lesser curvature, and thus those patients with DUs should be screened for IM and followed-up for GC development (18).

Concomitant gastric and duodenal ulcer (CGDU) disease, which is defined as the co-existence of ulcers in the stomach and duodenum, is a special type of PUD and is clinically characterized by the predominant symptoms of epigastric pain accompanied by bloating, acid reflux/regurgitation, bleeding, nausea, vomiting, poor appetite, early satiety and 
heartburn $(10,19)$. However, the prevalence of IM in patients with CGDU disease has not been fully elucidated by studies using a large number of patients. Additionally, the potential risk factors for IM present in patients with CGDU disease require identification, as does the prevalence of $H$. pylori infection and the pathological characteristics in Chinese patients with CGDU disease.

Therefore, the aim of the present study was to determine the prevalence of IM and the associated risk factors in Chinese patients with CGDU disease.

\section{Patients and methods}

Inclusion and exclusion criteria. The medical records of consecutive patients who underwent esophagogastroduodenal endoscopy due to upper gastrointestinal symptoms between January 2002 and August 2011 at the First Affiliated Hospital of Nanchang University (Nanchang, China) were retrospectively reviewed, and the patients who were diagnosed with CGDU disease were selected for further analysis. The study was approved by Ethics Committee of the First Affiliated Hospital of Nanchang University and informed consent was obtained from each individual. The upper gastrointestinal symptoms included epigastric pain, bloating, acid reflux, bleeding, nausea, vomiting, poor appetite, early satiety, and heartburn. Patients who had a history of anti-H. pylori therapy, or who had been treated with non-steroidal anti-inflammatory drugs (NSAIDs) over the prior three months or with histamine $\mathrm{H}_{2}$-receptor antagonists or proton pump inhibitors over the prior four weeks were excluded.

At endoscopy, an ulcer was defined as a deep mucosal break with a diameter of $\geq 5 \mathrm{~mm}$ in the stomach or duodenum (for active ulcers) (10), or by evidence of scarring or deformity. CGDU disease was diagnosed when there were ulcers in the stomach and duodenum, with or without complications (i.e., gastrointestinal bleeding and perforation). Cases with histologically confirmed GC and dysplasia were excluded.

As numerous patients had more than one endoscopy performed during the period of study, the first endoscopy was used as the index. However, when a patient had CGDU disease and/or IM, the first endoscopy at which the CGDU disease and/or IM was diagnosed was used as the index. Thus, each patient had one representative endoscopy (20). In addition, as a number of patients had more than one ulcer in the same and/or different sites of stomach or duodenum, the ulcer with the largest diameter was considered as the index ulcer; for these cases, the size of the GU or DU was included in the analysis.

Diagnosis of H. pylori infection and upper gastrointestinal symptoms. At the time of endoscopic examination, biopsies were obtained from the antrum $(\mathrm{n}=2)$ and body mucosa $(\mathrm{n}=2)$ without the ulcer, and the edge of each ulcer $(n \geq 2)$. One antral biopsy was used for an in-house rapid urease test (RUT), and the remaining biopsies were used for histological examinations and Giemsa staining. H. pylori infection was defined if the RUT, histological examination or Giemsa staining was positive.

The presence of upper gastrointestinal symptoms characteristic of CGDU $(10,19)$, including epigastric pain, bloating, acid reflux/regurgitation, bleeding, nausea, vomiting, poor appetite, early satiety and heartburn, was recorded.
Histological examinations. Histological examinations were performed by experienced pathologists at the First Affiliated Hospital of Nanchang University. Histological changes, including chronic and active inflammation, lymphoid aggregates or follicles, atrophy, and, in particular, IM and grading, were determined according to the updated Sydney System (21).

Statistical methods. Data are presented as the mean \pm standard deviation (SD) or percentage rate. The t-test (for numerical data) and the $\chi^{2}$-test or Fisher's exact test (for categorical data) were used to estimate the significance of the differences, which were described by the odds ratio (OR) and $95 \%$ confidence interval (CI). Variables with $\mathrm{P}<0.10$ in the univariate analysis were entered as candidate risk factors in the multivariate forward stepwise logistic regression analysis. All statistical analyses were performed by the Statistical Package for Social Science software suite (version 17.0; SPSS, Inc., Chicago, IL, USA). $\mathrm{P}<0.05$ was considered to indicate a statistically significant difference, and all reported P-values were two-sided.

\section{Results}

Prevalence and endoscopic findings of CGDUs in patients undergoing oesophagogastroduodenoscopy endoscopy. Among the 204,073 consecutive patients who underwent esophagogastroduodenal endoscopy with a defined index endoscopic procedure, 2,397 patients were diagnosed with CGDU disease, which accounted for $1.2 \%$ of the overall cases. Of these 2,397 patients, 248 were excluded. The reasons for exclusion were GC $(\mathrm{n}=11)$, dysplasia $(\mathrm{n}=15)$, a history of anti-H. pylori therapy $(\mathrm{n}=43)$, or treatment with NSAIDs, $\mathrm{H}_{2}$-receptor antagonists or proton pump inhibitors $(\mathrm{n}=179)$. Thus, 2,149 cases $(1,610$ males and 539 females, with a mean age \pm SD of $46.0 \pm 13.5$ years) with CGDU disease were included in the study. Of these cases, index GUs in the gastric antrum, gastric incisura and gastric corpus (including the gastric fundus and cardia) were present in 1,367, 718 and 64 cases, respectively, and index DUs in the superior, inferior, anterior and posterior walls were present in 489, 436, 1,031 and 193 cases, respectively. Two or more GUs and DUs were found in 279 and 312 patients, respectively. Gastrointestinal bleeding and perforation occurred in 216 and 19 patients, respectively. The mean sizes of the index GUs and DUs were $5.7 \pm 2.7 \mathrm{~mm}$ and 7.2 $\pm 3.4 \mathrm{~mm}$, respectively (Table I).

Symptomatic pattern, H. pylori infection and IM in patients with CGDU disease. The predominant symptom of the patients with CGDU disease was epigastric pain (77.2\%) accompanied by other symptoms, including bloating (57.1\%), acid reflux/regurgitation (48.8\%), bleeding (10.0\%), nausea (34.3\%), vomiting $(9.4 \%)$, poor appetite $(34.6 \%)$, early satiety (11.3\%) and heartburn (31.3\%) (Table II).

Of the 2,149 patients with CGDU disease, 1,486 (69.1\%) patients were positive for RUT, histological examination and/or Giemsa staining, and thus defined as having an ongoing H. pylori infection (Table II). IM was observed in $180(8.4 \%)$ patients, of which $128(71.1 \%)$ were male and $52(28.9 \%)$ were female, and $153(85.0 \%)$ showed mild grade, 26 (14.4\%) showed moderate grade and one $(0.6 \%)$ showed severe grade IM (Table II). 
Table I. Endoscopic findings of patients with CGDU disease.

\begin{tabular}{|c|c|}
\hline Parameter & Measure \\
\hline \multicolumn{2}{|l|}{ Exclusion (n) } \\
\hline GC & 11 \\
\hline Dysplasia & 15 \\
\hline History of anti-H. pylori therapy & 43 \\
\hline $\begin{array}{l}\text { Treated with NSAIDs, } \mathrm{H}_{2} \text {-receptor antagonists } \\
\text { or proton pump inhibitors }\end{array}$ & 179 \\
\hline \multicolumn{2}{|l|}{ Inclusion (n) } \\
\hline Benign CGDU & 2149 \\
\hline \multicolumn{2}{|l|}{ Gender (n) } \\
\hline Male & 1610 \\
\hline Female & 539 \\
\hline \multicolumn{2}{|l|}{ Site of index GUa (n) } \\
\hline Gastric antrum & 1367 \\
\hline Gastric incisura & 718 \\
\hline Gastric corpus ${ }^{\mathrm{b}}$ & 64 \\
\hline \multicolumn{2}{|l|}{ Site of index DU' (n) } \\
\hline Superior wall & 489 \\
\hline Inferior wall & 436 \\
\hline Anterior wall & 1031 \\
\hline Posterior wall & 193 \\
\hline \multicolumn{2}{|l|}{ Complications (n) } \\
\hline Gastrointestinal bleeding & 216 \\
\hline Perforation & 19 \\
\hline \multicolumn{2}{|l|}{ Size of CGDU $(\mathrm{mm} \pm \mathrm{SD})$} \\
\hline GU & $5.7 \pm 2.7$ \\
\hline DU & $7.2 \pm 3.4$ \\
\hline
\end{tabular}

a591 patients had GUs at two or more sites within the stomach $(n=279)$ or at two or more sites within the duodenum $(n=312)$. bincluding four cases in the gastric fundus and one in the cardia, all without IM. CGDU, concomitant gastric and duodenal ulcer; GC, gastric cancer; H. pylori, Helicobacter pylori; NSAIDs, non-steroidal anti-inflammatory drugs; GU, gastric ulcer; DU, duodenal ulcer; IM, intestinal metaplasia.

Correlations of demographic, clinical and endoscopic characteristics and $H$. pylori infection with IM. Patients with IM were significantly older than those without IM $(52.4 \pm 11.8$ vs. $45.4 \pm 13.6$ years; $\mathrm{P}<0.001)$. However, no significant difference was identified in the incidence of IM between the males and females (8.0 vs. 9.6\%; OR=0.809, $\left.95 \% \mathrm{CI}=0.577-1.134, \chi^{2}=1.516, \mathrm{P}=0.218\right)$. No differences were found in the rates of IM that occurred for any of the symptoms, nor between different sizes of GU or DU ( $\mathrm{P}>0.05)$. $H$. pylori infection was detected in $81.7 \%$ of the patients with IM, which was significantly higher than the incidence $(68.0 \%)$ in the patients without IM $(\mathrm{OR}=2.096,95 \% \mathrm{CI}=1.420-3.093$, $\chi^{2}=14.431, \mathrm{P}<0.001$; Table III). Also, GUs at the gastric incisura were associated with an increased rate of IM, compared with the rate of IM associated with GUs at other locations (56.7 vs. 43.3\%; OR=2.872, 95\% CI=2.107-3.915, $\chi^{2}=47.757$, $\mathrm{P}<0.001)$. Multivariate analysis identified age $\geq 50$ years
Table II. Symptomatic pattern, H. pylori infection and IM in 2,149 patients with CGDU disease.

\begin{tabular}{|c|c|}
\hline Parameter & Percentage \\
\hline \multicolumn{2}{|l|}{ Upper gastrointestinal symptom ${ }^{\mathrm{a}}$} \\
\hline Epigastric pain $(n=1660)$ & 77.2 \\
\hline Bloating $(\mathrm{n}=1228)$ & 57.1 \\
\hline Acid reflux/regurgitation $(n=1050)$ & 48.8 \\
\hline Bleeding $(n=216)$ & 10.0 \\
\hline Nausea $(n=737)$ & 34.3 \\
\hline Vomiting (n=202) & 9.4 \\
\hline Poor appetite $(n=744)$ & 34.6 \\
\hline Early satiety $(\mathrm{n}=243)$ & 11.3 \\
\hline Heartburn $(n=673)$ & 31.3 \\
\hline \multicolumn{2}{|l|}{ H.pylori status } \\
\hline Positive $(\mathrm{n}=1486)$ & 69.1 \\
\hline Negative $(n=663)$ & 30.9 \\
\hline \multicolumn{2}{|l|}{$\mathrm{IM}$} \\
\hline Presence $(n=180)$ & 8.4 \\
\hline \multicolumn{2}{|l|}{ Gender } \\
\hline Male $(n=128)$ & 71.1 \\
\hline Female $(n=52)$ & 28.9 \\
\hline \multicolumn{2}{|l|}{ Extent } \\
\hline Moderate/severe $(n=27)$ & 15.0 \\
\hline Mild (n=153) & 85.0 \\
\hline Absence $(n=1969)$ & 91.6 \\
\hline
\end{tabular}

$\left(\mathrm{OR}=2.606,95 \% \mathrm{CI}=1.889-3.597, \chi^{2}=34.000, \mathrm{P}<0.001\right)$, GUs at the gastric incisura $(\mathrm{OR}=2.644,95 \% \mathrm{CI}=1.926-3.630$, $\left.\chi^{2}=36.142, \mathrm{P}<0.001\right)$ and $H$. pylori infection $(\mathrm{OR}=2.338$, $\left.95 \% \mathrm{CI}=1.573-3.474, \chi^{2}=17.648, \mathrm{P}<0.001\right)$ as independent risk factors for the development of IM (Table III).

In addition, the mean age of the patients with moderate and severe IM was $56.0 \pm 10.1$ years, which was slightly older than that of the patients with mild IM $(51.8 \pm 12.0)$ $(\mathrm{P}=0.091)$. Moderate and severe IM were more frequently detected in males than in females $(18.8 \%$ vs. $5.8 \%$; OR=3.769, $95 \% \mathrm{CI}=1.083-13.121, \chi^{2}=4.887, \mathrm{P}=0.036$ ) (data not shown).

\section{Discussion}

The prevalence of PUD, diagnosed predominately by endoscopy (22), has been reported as $4.1 \%$ in the general adult population of northern Sweden (23), and $2.7 \%$ in Italian individuals without evidence of $H$. pylori infection or prior exposure to NSAIDs (10). In the USA, the prevalence of GUs, DUs and CGDUs has been reported to be 3, 6 and $0.8 \%$, respectively (24). In China, the endoscopic detection rate of PUD has been reported as $17.2 \%$ (25). However, the prevalence 
Table III. Correlation of demographic, clinical and endoscopic characteristics and H. pylori infection with IM.

\begin{tabular}{|c|c|c|c|c|c|c|}
\hline \multirow[b]{2}{*}{ Parameter } & \multirow{2}{*}{$\begin{array}{c}\text { With IM } \\
n=180\end{array}$} & \multirow{2}{*}{$\begin{array}{c}\text { Without IM } \\
n=1969\end{array}$} & \multicolumn{2}{|c|}{ Univariate analysis } & \multicolumn{2}{|c|}{ Multivariate analysis } \\
\hline & & & OR $(95 \% \mathrm{CI})$ & $\mathrm{P}$ & OR $(95 \% \mathrm{CI})$ & $\mathrm{P}$ \\
\hline \multicolumn{7}{|l|}{ Age in years } \\
\hline$\geq 50$ & $108(60.0 \%)$ & $700(35.6 \%)$ & $2.719(1.990-3.716)$ & $<0.001$ & $2.606(1.889-3.597)$ & $<0.001$ \\
\hline$<50$ & $72(40.0 \%)$ & $1269(64.4 \%)$ & & & & \\
\hline \multicolumn{7}{|l|}{ Gender } \\
\hline Male & $128(71.1 \%)$ & $1482(75.3 \%)$ & $0.809(0.577-1.134)$ & 0.218 & & \\
\hline Female & $52(28.9 \%)$ & $487(24.7 \%)$ & & & & \\
\hline \multicolumn{7}{|l|}{ Upper GI symptoms } \\
\hline Epigastric pain & $133(73.9 \%)$ & $1527(77.6 \%)$ & $0.819(0.578-1.161)$ & 0.262 & & \\
\hline Bloating & $107(59.4 \%)$ & $1121(56.9 \%)$ & $1.109(0.813-1.513)$ & 0.514 & & \\
\hline Sour regurgitation & $82(45.6 \%)$ & $968(49.2 \%)$ & $0.865(0.637-1.175)$ & 0.354 & & \\
\hline Bleeding & $20(11.1 \%)$ & $196(10.0 \%)$ & $1.131(0.694-1.841)$ & 0.621 & & \\
\hline Nausea & $58(32.2 \%)$ & $679(34.5 \%)$ & $0.903(0.652-1.251)$ & 0.541 & & \\
\hline Vomiting & $18(10.0 \%)$ & $184(9.3 \%)$ & $1.078(0.647-1.795)$ & 0.773 & & \\
\hline Poor appetite & $66(36.7 \%)$ & $678(34.4 \%)$ & $1.103(0.803-1.515)$ & 0.543 & & \\
\hline Early satiety & $25(13.9 \%)$ & $218(11.1 \%)$ & $1.296(0.830-2.022)$ & 0.253 & & \\
\hline Heartburn & $61(33.9 \%)$ & $612(31.1 \%)$ & $1.137(0.823-1.570)$ & 0.437 & & \\
\hline \multicolumn{7}{|l|}{ Site of index $\mathrm{GU}^{\mathrm{a}}$} \\
\hline Gastric antrum & $76(42.2 \%)$ & $1291(65.6 \%)$ & $0.384(0.281-0.523)$ & $<0.001$ & & \\
\hline Gastric incisura & $102(56.7 \%)$ & $616(31.3 \%)$ & $2.872(2.107-3.915)$ & $<0.001$ & $2.644(1.926-3.630)$ & $<0.001$ \\
\hline Gastric corpus $^{\mathrm{b}}$ & $2(1.1 \%)$ & $62(3.1 \%)$ & $0.346(0.084-1.425)$ & 0.166 & & \\
\hline \multicolumn{7}{|l|}{ Site of index DU } \\
\hline Superior wall & $35(19.4 \%)$ & $454(23.1 \%)$ & $0.805(0.549-1.182)$ & 0.268 & & \\
\hline Inferior wall & $30(16.7 \%)$ & $406(20.6 \%)$ & $0.770(0.513-1.157)$ & 0.207 & & \\
\hline Anterior wall & $96(53.3 \%)$ & $935(47.5 \%)$ & $1.264(0.931-1.716)$ & 0.133 & & \\
\hline Posterior wall & $19(10.6 \%)$ & $174(8.8 \%)$ & $1.217(0.738-2.008)$ & 0.440 & & \\
\hline Size of GU in mm & $5.6 \pm 2.9$ & $5.7 \pm 2.7$ & & 0.469 & & \\
\hline Size of DU in $\mathrm{mm}$ & $7.3 \pm 3.9$ & $7.1 \pm 3.3$ & & 0.469 & & \\
\hline H. pylori infection & $147(81.7 \%)$ & $1339(68.0 \%)$ & $2.096(1.420-3.093)$ & $<0.001$ & $2.338(1.573-3.474)$ & $<0.001$ \\
\hline
\end{tabular}

${ }^{a} 591$ patients had GUs at two or more sites within the stomach $(\mathrm{n}=279)$ or at two or more sites within the duodenum ( $\left.\mathrm{n}=312\right)$. ${ }^{\mathrm{b}}$ Including four cases in the gastric fundus and one in the cardia, all without IM. H. pylori, Helicobacter pylori; IM, intestinal metaplasia; OR, odds ratio; CI, confidence interval; GI, gastrointestinal; GU, gastric ulcer; DU, duodenal ulcer.

of CGDU disease has not been considered in these studies, but was calculated as $1.2 \%$ in the population of Chinese patients in the present study.

$H$. pylori infection and NSAIDs and/or aspirin use remain the main determinants of PUD $(9,11)$; the ultimate indication that $H$. pylori infection is the main cause of PUD is the permanent cure of ulcers upon eradication of the infection $(26,27)$. In addition, early $H$. pylori eradication is also associated with a decreased risk of GC in patients with PUD (28). Therefore, it is critical to identify $H$. pylori infection in patients with PUD. A previous study reported that the prevalence of $H$. pylori infection was $77.6 \%$ in bleeding PUD in Japanese patients (29). Another study conducted in Poland detected $H$. pylori infection in $72.5 \%$ of GU patients, in $83.6 \%$ of DU patients and in $76.9 \%$ of CGDU patients (30). However, the prevalence of $H$. pylori infection in Chinese patients with CGDU disease has been poorly reported. In the present study, the prevalence of $H$. pylori infection in a large cohort of patients with CGDU disease was found to be $69.1 \%$. Based on the findings of a previous study (31), eradication treatment for $H$. pylori infection should be adopted to heal ulcers and reduce relapse.

The role of $H$. pylori infection in the development of IM in patients with CGDU disease has not been well elucidated. The present study observed that the prevalence of $H$. pylori infection in CGDU disease patients with and without IM was $81.7 \%$ and $68.0 \%$, respectively, and multivariate analysis showed that $H$. pylori infection was an independent risk factor for IM in patients with CGDU disease. This indicates that $H$. pylori infection must be eradicated in these patients for a new reason - prevention of the development of IM and thus termination of the progression to neoplasia (32), which ultimately hinders the occurrence of GC. 
The associations of age and gender with IM in patients with CGDU disease have, to the best of our knowledge, not been reported previously. In the present study, multivariate analysis revealed that age $\geq 50$ years was an independent risk factor for IM, which is consistent with previous studies reporting that the incidence of IM increases with age $(8,33)$. In addition, although the overall incidence of IM between the male and female patients was not observed to be significantly different, moderate and severe IM occurred more commonly in males than in females, suggesting a high degree of IM in male patients, which is prone to developing into GC. These findings further supported the theory that increased age and male gender were risk factors for the development and increasing severity of premalignant gastric lesions, including IM, and thus for the development of GC (7).

IM is often unevenly distributed throughout the stomach (32), and occurs most frequently along the lesser curvature from the cardia to the pylorus, particularly in the transitional zones (mainly from the corpus to the antrum) (34). A previous study revealed that the prevalence of IM was higher in the antral mucosa than in the body mucosa, and the highest frequency of IM was detected in patients with GUs (14). Thus, the specific ulcer sites that are closely associated with the development of IM should be determined, particularly in patients with CGDU disease. In the present study, multivariate analysis identified that ulceration at the gastric incisura was an independent risk factor for IM. In addition, no difference was identified in the rates of IM among the ulcers at different duodenal sites. These findings suggest that ulcers at the gastric incisura are closely associated with the development of IM. Notably, in the present study, no association was identified between any of the symptoms, as well as the size of the ulcers, with IM, indicating that these two factors were not predictive factors for IM.

The present study has certain limitations that may affect the interpretation of the findings. Sub-analyses were not performed for the subtypes of IM [complete vs. incomplete IM, the latter of which has been suggested as a risk factor for GC development (32)]. The difference in the prevalence of IM between CGDUs and GUs alone was not evaluated in the present study. Additionally, this was a retrospective study, and thus there was no regular follow-up of the patients; follow-up is essential to determine the long-term histological consequences (i.e., dysplasia and GC) of patients with CGDU disease and IM. Therefore, the clinical significance of the risk factors that were identified to be associated with IM in patients with CGDU disease requires verification in long-term prospective studies.

In conclusion, CGDUs were observed in $1.2 \%$ of the patients in the single-site Chinese population of the present study. IM occurred in $8.4 \%$ of those patients with CGDU disease. H.pylori infection, age $\geq 50$ years and ulceration at gastric incisura were identified as independent risk factors for IM in patients with CGDU disease, whereas males were observed to be more prone to moderate/severe IM than females. Further long-term prospective investigation is required to verify these findings.

\section{Acknowledgements}

The authors are grateful to all the endoscopists and pathologists at the First Affiliated Hospital of Nanchang University for their technical expertise and help in completing this study. The authors also thank Medjaden Bioscience Ltd. (Hong Kong, China) for assisting in the preparation of this manuscript. This study was supported by grants from the Natural Science Foundation of Jiangxi Province (No. 20122BAB215010) and the National Major Scientific and Technological Special Project for 'Significant New Drugs Development' during the Twelfth Five-Year Plan period (No. 2011ZX09302-007-03).

\section{References}

1. Danaei G, Vander Hoorn S, Lopez AD, Murray CJ and Ezzati M; Comparative Risk Assessment collaborating group (Cancers): Causes of cancer in the world: comparative risk assessment of nine behavioural and environmental risk factors. Lancet 366 : 1784-1793, 2005.

2. Catalano V, Labianca R, Beretta GD, Gatta G, de Braud F and Van Cutsem E: Gastric cancer. Crit Rev Oncol Hematol 71: 127-164, 2009.

3. Parkin DM, Bray F, Ferlay J and Pisani P: Global cancer statistics, 2002. CA Cancer J Clin 55: 74-108, 2005.

4. Chen JG, Zhu J, Parkin DM, et al: Trends in the incidence of cancer in Qidong, China, 1978-2002. Int J Cancer 119: 1447-1454, 2006.

5. Yang L: Incidence and mortality of gastric cancer in China. World J Gastroenterol 12: 17-20, 2006.

6. Correa P, Haenszel W, Cuello C, Tannenbaum S and Archer M: A model for gastric cancer epidemiology. Lancet 2: 58-60, 1975.

7. de Vries AC, van Grieken NC, Looman CW, et al: Gastric cancer risk in patients with premalignant gastric lesions: a nationwide cohort study in the Netherlands. Gastroenterology 134: 945-952, 2008.

8. Kim HJ, Choi BY, Byun TJ, et al: The prevalence of atrophic gastritis and intestinal metaplasia according to gender, age and Helicobacter pylori infection in a rural population. J Prev Med Public Health 41: 373-379, 2008 (In Korean).

9. Sbrozzi-Vanni A, Zullo A, Di Giulio E, et al: Low prevalence of idiopathic peptic ulcer disease: an Italian endoscopic survey. Dig Liver Dis 42: 773-776, 2010.

10. Malfertheiner P, Chan FK and McColl KE: Peptic ulcer disease. Lancet 374: 1449-1461, 2009.

11. Malfertheiner P, Megraud F, O'Morain CA, et al; European Helicobacter Study Group: Management of Helicobacter pylori infection - the Maastricht IV/ Florence Consensus Report. Gut 61: 646-664, 2012.

12. Lv SX, Gan JH, Wang CC, et al: Biopsy from the base of gastric ulcer may find gastric cancer earlier. Med Hypotheses 76: 249-250, 2011.

13. Molloy RM and Sonnenberg A: Relation between gastric cancer and previous peptic ulcer disease. Gut 40: 247-252, 1997.

14. Eidt $S$ and Stolte M: Prevalence of intestinal metaplasia in Helicobacter pylori gastritis. Scand J Gastroenterol 29: 607-610, 1994.

15. Leung WK, Lin SR, Ching JY, et al: Factors predicting progression of gastric intestinal metaplasia: results of a randomised trial on Helicobacter pylori eradication. Gut 53: 1244-1249, 2004.

16. Tsukui T, Kashiwagi R, Sakane M, et al: Aging increases, and duodenal ulcer reduces the risk for intestinal metaplasia of the gastric corpus in Japanese patients with dyspepsia. J Gastroenterol Hepatol 16: 15-21, 2001.

17. Hansson LE, Nyrén O, Hsing AW, et al: The risk of stomach cancer in patients with gastric or duodenal ulcer disease. N Engl J Med 335: 242-249, 1996.

18. Cho SJ, Choi IJ, Kim CG, et al: Risk factors associated with gastric cancer in patients with a duodenal ulcer. Helicobacter 15: 516-523, 2010.

19. Drossman DA: The functional gastrointestinal disorders and the Rome II process. Gut 45 (Suppl 2): II1-II5, 1999.

20. Xia HH, Wong BC, Wong KW, et al: Clinical and endoscopic characteristics of non-Helicobacter pylori, non-NSAID duodenal ulcers: a long-term prospective study. Aliment Pharmacol Ther 15: 1875-1882, 2001.

21. Dixon MF, Genta RM, Yardley JH and Correa P: Classification and grading of gastritis. The updated Sydney System. International Workshop on the Histopathology of Gastritis, Houston 1994. Am J Surg Pathol 20: 1161-1181, 1996. 
22. Torpy JM, Lynm C and Golub RM: JAMA patient page. Peptic ulcer disease. JAMA 307: 1329, 2012.

23. Aro P, Storskrubb T, Ronkainen J, et al: Peptic ulcer disease in a general adult population: the Kalixanda study: a random population-based study. Am J Epidemiol 163: 1025-1034, 2006.

24. Bao Y, Spiegelman D, Li R, Giovannucci E, Fuchs CS and Michaud DS: History of peptic ulcer disease and pancreatic cancer risk in men. Gastroenterology 138: 541-549, 2010.

25. Li Z, Zou D, Ma X, et al: Epidemiology of peptic ulcer disease: endoscopic results of the systematic investigation of gastrointestinal disease in China. Am J Gastroenterol 105: 2570-2577, 2010.

26. Rauws EA and Tytgat GN: Cure of duodenal ulcer associated with eradication of Helicobacter pylori. Lancet 335: 1233-1235, 1990.

27. Malfertheiner P, Leodolter A and Peitz U: Cure of Helicobacter pylori-associated ulcer disease through eradication. Baillieres Best Pract Res Clin Gastroenterol 14: 119-132, 2000.

28. Wu CY, Kuo KN, Wu MS, Chen YJ, Wang CB and Lin JT: Early Helicobacter pylori eradication decreases risk of gastric cancer in patients with peptic ulcer disease. Gastroenterology 137: 1641-1648.e2, 2009.

29. Shimizu S, Nakamura S, Kishino M, Konishi H and Shiratori K: Role of antithrombotic therapy and nonsteroidal anti-inflammatory drug use in bleeding gastroduodenal ulcers. Intern Med 48: 631-637, 2009.
30. Konturek SJ, Bielański W, Płonka M, et al: Helicobacter pylori, non-steroidal anti-inflammatory drugs and smoking in risk pattern of gastroduodenal ulcers. Scand J Gastroenterol 38: 923-930, 2003

31. Arkkila PE, Seppälä K, Kosunen TU, et al: Helicobacter pylori eradication as the sole treatment for gastric and duodenal ulcers. Eur J Gastroenterol Hepatol 17: 93-101, 2005.

32. Dinis-Ribeiro M, Areia M, de Vries AC et al; MAPS Participants: Management of precancerous conditions and lesions in the stomach (MAPS): guideline from the European Society of Gastrointestinal Endoscopy (ESGE), European Helicobacter Study Group (EHSG), European Society of Pathology (ESP), and the Sociedade Portuguesa de Endoscopia Digestiva (SPED). Endoscopy 44: 74-94, 2012

33. Yee YK, Wong KW, Hui CK, et al: Prevalence and time trend of intestinal metaplasia in Hong Kong. J Gastroenterol Hepatol 24: 896-899, 2009

34. Van Zanten SJ, Dixon MF and Lee A: The gastric transitional zones: neglected links between gastroduodenal pathology and Helicobacter ecology. Gastroenterology 116: 1217-1229, 1999. 